\title{
REDES SOCIAIS E O DIREITO À PRIVACIDADE
}

\author{
Bárbara Pinho Coelho
}

Universidade do Oeste Paulista - UNOESTE, Pós- Graduação em Avaliação do Ensino e da Aprendizagem, Presidente Prudente, SP. Universidade Estadual de Londrina - UEL, Programa de Mestrado em Direito Negocial, Londrina, PR. Email: barbara4161@hotmail.com

\section{RESUMO}

A internet é considerada um meio de comunicação em massa e por isso é constante a exposição dos usuários nas redes sociais. Recentemente, o Facebook, uma das maiores redes Sociais atualmente no mundo, contratou uma agência chamada Datalogix com o fim de espionar e coletar o desejo de seus usuários e desta forma direcionar os comerciantes virtuais ao seu público alvo, essa sondagem ocorre de forma online ou off-line. Isso, sem dúvida, viola o direito adas não trouxeram solução para eventuais problemas trazidos pela internet, como o Marco Civilconstitucional da privacidade dos internautas que estão sendo vigiados constantemente. As legislações cri da Internet, foram capazes de ponderar o conflito de direitos violados pelas Redes Sociais.

Palavras-chave: Redes Sociais. Privacidade. Direito. Ponderação.

\section{NETWORKS AND THE RIGHT TO PRIVACY}

\begin{abstract}
The Internet is considered a means of mass communication and therefore the exposure of users in social networks is constant. Recently, Facebook, one of the largest social networks in the world, has hired an agency called Datalogix in order to spy on and collect the desire of its users and in this way to direct the virtual merchants to its target audience, this survey occurs online or Off line. This undoubtedly violates the constitutional right of the privacy of Internet users who are constantly being watched and not even the legislation created to solve any problems brought about by the Internet, such as the Civil Internet Framework, were able to consider the conflict of rights violated by the Networks Social.
\end{abstract}

Keywords: Social Networks. Privacy. Right. Weighting.

\section{INTRODUÇÃO}

A internet facilitou e muito a vida das pessoas. Permitiu a aproximação de pessoas, possibilitou relações interpessoais e negociais em qualquer lugar do mundo.

Por outro lado essa ferramenta que até hoje encontra-se em evolução sofre um embate jurídico, pois violou alguns direitos fundamentais descritos no art. 5으 da Constituição Federal, como a privacidade. A ponderação neste caso torna-se uma saída permitida pelo Direito para solucionar eventuais conflitos entre a internet, por meio das redes sociais e a violação de certos direitos.

A metodologia utilizada foi justamente o método dedutivo, ou seja, ao identificar um problema (premissa central) por um meio lógico, capaz de permitir o convívio social, chegou-se à conclusão de que a ponderação é necessária.

\section{PANORAMA GERAL SOBRE O CONFLITO}


Com o advento das redes sociais passamos a vivenciar a nova era da globalização, eis que possibilitaram a inovação na maneira de se comunicar, encurtando ainda mais as distâncias com a comunicação em tempo real, pela troca de mensagens e videochamadas.

Neste momento, faz-se necessário definir o que se entende por redes sociais. Estas são classificadas como um serviço (social networking service), uma plataforma baseada na internet, para a formação de redes sociais ou relações sociais entre pessoas, que compartilham atividades, interesses ou conexões da vida real. Comumente, os usuários deste serviço são representados por um perfil, suas relações sociais, dentre outros serviços adicionais. Desta forma, a plataforma permite o compartilhamento de fotos, vídeos, mensagens, notícias, e mais uma variedade de opções.

Grandes corporações se formaram, a exemplo do Facebook, Twitter, e o ultrapassado Orkut, desativado em setembro de 2014. Com as redes sociais, desenvolveu-se de forma mais sedimentada o marketing digital, que nos dias atuais representa um importante meio de divulgação de empresas, marcas e produtos.

Inobstante esses avanços, surgiu-se uma preocupação justificada pela influência e invasão exercida pelas redes sociais na vida das pessoas, precipuamente em relação à liberdade de expressão, a intimidade, e a privacidade, todos os direitos consagrados na Carta Magna de 1988.

Segundo Jennings e Fena, 2000, p.16 (apud Hirata, 2014, p.17):

É desnecessário justificar a importância e a motivação de escrever sobre o fenômeno das redes sociais e suas implicações na privacidade das pessoas. Trata-se de questão cotidiana na nossa sociedade contemporânea, atingindo direta ou indiretamente a enorme maioria da população mundial. É função primordial do direito tratar dessas novas situações, adequar-se a elas e enfrentá-las com seus instrumentos, já existentes ou inéditos, da melhor forma possível. (grifo nosso)

Essas implicações na vida das pessoas, por consequência, coloca dois direitos em conflito, ambos de índole constitucional, quais sejam, os direitos à liberdade de expressão e a privacidade, inseridos no artigo 5. - , incisos IX e $X$, respectivamente.

A liberdade de expressão (GARCIA, 2003, p. 285): "consiste na faculdade de expressar livremente o próprio pensamento, ideias e opiniões, por qualquer meio de difusão".

Logo é o direito do cidadão se expressar sobre qualquer coisa, mas esse direito possui duas ressalvas: o discurso racista que caracteriza crime e a vedação do anonimato. Esta última exceção nos interessa quando falamos de redes sociais já que esta é a ferramenta utilizada como escudo para pessoas que visam o anonimato, por meio de perfils falsos. Tanto é que, o Whatsapp, por exemplo, tem se tornado alvo de bloqueios pela justiça brasileira com o fim de identificar usuários criminosos que se escondem por de trás desta rede social.

No entender de Cunha Júnior (2012, p. 720), a Constituição Federal de 1988, oferece, expressamente, guarida ao direito à privacidade:

Que consistente fundamentalmente na faculdade que tem cada indivíduo de obstar a intromissão de estranhos na sua vida particular e familiar, assim, como de impedir-lhes o acesso a informação sobre a privacidade e intimidade de cada um, e também proibir que sejam divulgadas informações sobre esta área da manifestação existencial do ser humano.

No âmbito eletrônico, igualmente, a Lei n. 12.965, de 23 de abril de 2014, conhecida como o Marco Civil da Internet, estabelece como princípios do uso da internet no Brasil, "a garantia da 
liberdade de expressão, comunicação e manifestação de pensamento, nos termos da Constituição Federal, e a proteção da liberdade", conforme dispõe o artigo 3.․, incisos I e II:

Assim, sobressai a seguinte indagação: como balancear a garantia da privacidade e a liberdade de expressão? Direito tidos como fundamentais, e que se encontram no bojo do aclamado artigo 50 , da $\mathrm{CF} / 88$.

Recentemente, uma das redes sociais de maior impacto econômico-social: o Facebook firmou parceria com uma agência de coleta de dados chamada Datalogix, para obter o rastreamento dos hábitos de consumos de seus usuários, enquanto estão on-line, e também offline. E assim, os anunciantes passariam a ter um maior feedback em suas vendas.

Neste sentido, muito tem-se discutido se esta prática configuraria invasão da privacidade das pessoas que utilizam os serviços da referida rede social, posto que, a coleta de informações e de dados independe da anuência destas, e ainda que, seja exclusivamente para prática comercial de divulgação de produtos e serviços conforme as preferências de cada usuário, interfere na vida privada.

Em que pese estes serviços disponibilizarem em suas configurações restrições de segurança e privacidade, qualquer mínimo erro pode acarretar sérios prejuízos à imagem e a outros direitos da personalidade, passíveis de indenização em nosso ordenamento jurídico.

Por analogia, classifica-se a internet, e aqui se insere as redes sociais, com um meio de comunicação em massa. Consequentemente, amolda-se perfeitamente aos conceitos de privacidade e intimidade aos dados que trafegam pelo cyberspace.

Como cediço, é indispensável adequar a legislação editada em outra realidade social através de um processo interpretativo, com a finalidade de se atender aos anseios sociais e desafios da vida contemporânea, conforme os artigos 4.ㅇ e 5.으, da Lei de Introdução às Normas do Direito Brasileiro (Decreto-Lei n.o 4.657, de 04 de setembro de 1942).

Até mesmo a Carta Magna de 1998, passa por um processo interpretativo que visa adequar à realidade vivenciada na qual está inserida, a chamada: Mutação Constitucional, sem que se altere expressamente seu texto legal. Segundo Bulos (2010, p. 118) a descreve como o "fenômeno pelo qual os textos constitucionais são alterados sem revisões ou emendas", para ele:

O fenômeno das mutações constitucionais, portanto, é uma constante na vida dos Estados. As constituições, como organismos vivos que são, acompanham o evoluir das circunstâncias sociais, políticas, econômicas, que, se não alteram o texto na letra e na forma, modificam-no na substancia, no significado, no alcance e nos seus dispositivos. (grifo nosso)

Com efeito, a legislação interpretada às luzes da $\mathrm{CF} / 88$, não puderam prever todas as mudanças sociais e tecnológicas que estavam por vir. Com isso, deve-se realizar uma hermenêutica com o escopo de inserir as problemáticas que podem surgir com as redes sociais, especialmente quando este serviço mitiga ou aniquila a privacidade e a intimidade.

De todo modo, vislumbrando-se quaisquer violações a honra, a imagem, a intimidade e a vida privada, utilizando-se como meio deflagrador as redes sociais, ou a internet em sentido lato sensu, serão passíveis de indenização, nos termos dos artigos 186, 187 cumulado com o artigo 927, todos do Código Civil.

Poderá eventualmente, configurar ilícitos de natureza penal, a serem devidamente apurados e coibidos para desestimular a prática reiterada de tais condutas. Aliás, recentemente a Lei 12.737 de 30 de Novembro de 2012 incluiu no Código Penal um rol de delitos informáticos, inclusive o art. 154-A - Invasão de Dispositivo Informático. 


\section{CONCLUSÃO}

A internet é uma poderosa ferramenta utilizada nos dias de hoje. Permite a aproximação de pessoas, realização de negócios, transmissão ao vivo que antes era restrita a programas de televisão, mas em contrapartida este instrumento favorece a sondagem tanto para o bem quanto para o mau.

Explico. Mesmo que o usuário esteja offline, ou seja, desconectado da internet é possível que empresas, por exemplo, detectem os sites mais acessados pelo individuo e assim redirecione suas ofertas, como no caso do Facebook que contratou uma empresa especializada neste tipo de sondagem para que depois fornecesse tais informações a seus patrocinadores e estes efetuassem suas propagandas. Por outro lado, o mesmo artefato pode ser empregado para práticas criminosas com invasão de smartphones e computadores para roubar senha de aplicativos de bancos, fotos e etc.

Tudo isso deságua no embate do uso da internet, em especial das redes sociais e o direito fundamental à privacidade.

O Marco Civil da Internet (Lei 12.965/14) veio com o fim de tentar regularizar o uso da internet no Brasil e trouxe dentre as suas premissas o direito a privacidade, mas difícil são os meios de controle da privacidade em um ambiente virtual totalmente instável, batizado como "terra de ninguém".

Analisando friamente a legislação existente é possível o equilíbrio desta relação, o que falta é interpretação e aplicação severa, com punições graves a violações do direito de privacidade no âmbito penal, civil e administrativo.

No âmbito penal com a punição por incurso no crime descrito no art. 154-A do Código Penal, o problema é identificar o verdadeiro autor da invasão, já que estes se utilizam de perfils falsos e IPs diferentes. O mesmo problema se põe no âmbito civil, por meio da reparação de danos, em que o autor é acobertado pela internet e redes sociais.

A esfera administrativa vem se revelando a mais eficaz e imediatista nestes casos, onde a própria rede social ou site permite aos usuários realizar denúncia sobre alguma violação ocorrida e assim alcançar uma solução rápida, seja por meio de bloqueio, exclusão ou afim.

Percebe-se que o Direito jamais acompanhará a evolução tecnológica, mas podemos afirmar que a legislação para equilibrar o uso da internet e a privacidade existe. A insuficiência reside justamente em sua aplicação e na criação de mecanismos eficazes e ágeis para solucionar tais problemas.

\section{REFERÊNCIAS BIBLIOGRÁFICAS}

BRASIL. Constituição Federal. Brasília: Senado Federal, 1998.

. Lei 12.965 de 23 de Abril de 2014. Estabelece princípios, garantias, direitos e deveres para

o uso da Internet no Brasil. Disponível em: <http://www.planalto.gov.br/ccivil_03/_ato20112014/2014/lei/l12965.htm>. Acesso em: 01 de Agosto de 2017.

BULOS, Uadi Lammêgo. Curso de Direito constitucional. 4. Ed. São Paulo: Saraiva, 2010.

CUNHA JUNIOR, Dirley da. Curso de Direito Constitucional. 6. Ed. Salvador: Juspódium, 2012.

GARCIA, Guiomari Garson da Costa. Estado Democrático de Direito e liberdade de expressão e informação. Revista de Direito Constitucional e Internacional, v. 11, n. 42, jan./mar. 2003. 
HIRATA, Alessandro. 0 direito de Intimidade e ao Segredo na Sociedade Contemporânea. Birigui: Boreal, 2012. 